\title{
ANTI-FGM DISCOURSES AS CONSTRUCTED BY NGOS IN THE MAASAI COMMUNITY IN KENYA
}

\author{
by \\ Teriano Lesancha, BSW, Ryerson University, 2012
}

An MRP presented to Ryerson University

\author{
in partial fulfillment of the \\ requirements for the degree of \\ Master of Social Work \\ in the Program of \\ Social Work
}

Toronto, Ontario, Canada, 2017

(C) Teriano Lesancha 2017 


\section{AUTHOR'S DECLARATION FOR ELECTRONIC SUBMISSION OF A MRP}

I hereby declare that I am the sole author of this MRP. This is a true copy of the MRP, including any required final revisions.

I authorize Ryerson University to lend this MRP to other institutions or individuals for the purpose of scholarly research

I further authorize Ryerson University to reproduce this MRP by photocopying or by other means, in total or in part, at the request of other institutions or individuals for the purpose of scholarly research.

I understand that my MRP may be made electronically available to the public. 


\section{ABSTRACT \\ Anti-FGM CAMPAIGNS RE-COLONIZING MAASAI WOMEN \\ Master of Social Work, 2017 \\ Teriano Lesancha \\ Program of Social Work, Ryerson University}

This Major Research Paper conducted a critical discourse analysis of a documentary produced by NTV Kenya and AMREF Africa about eradicating Female Circumcision in the Maasai community in Kenya. This research sought to understand how the documentary constructed anti female genital mutilation (FGM) discourse. The main discourses were colonialism, saving the Maasai girl, and double patriarchy as is constructed by International NGOs. These discourses became evident through the language used, images displayed on the screen, gendered power relations and who is benefiting from these. Using the Maasai Female Experience (MFE) as a theoretical lens, I placed emphasis on how Maasai women are treated in the anti-FGM campaigns which is driven by international NGOs. African centered worldviews were also employed in this study by the use of MFE and Afrocentric theory of social change. Community development workers and social workers need to consider these discourses while working with Maasai women. They must be conscious about reproducing oppressive practices and stereotypes that has historically been used to marginalize Maasai women. 


\section{ACKNOWLEDGEMENTS}

It goes without saying that the African proverb of 'it takes a village to raise a child' holds true for this major research paper. It took a whole village and to thank everyone who supported me would not fit here. For those I did not mention by name, I take a bow in deep appreciation for your role in making this journey possible.

Special thanks go to Samantha Wehbi, my supervisor. Sam, you have been my mentor extraordinaire! I am still in awe at your patience as you guided me through my slow and tedious process of collecting my thoughts and theoretical footing. I cannot imagine anyone more suited for me in this role.

Jennifer Poole, thank you for holding my hand throughout this journey. Thank you for seeing in me what is invisible to me. You continued to inspire me and I continued to hear those words of encouragement that, I can do this. Thank you for your immeasurable support.

To my friends: Ndinda Msiska, Sharon Mulamba and Stacy-Anne Lettman with whom I debated several issues presented in this paper. Thank you for your immeasurable support. Thank you for your encouragement and for pulling me up every time I was feeling down.

To my brothers Kipas Lesancha and Saruni Lesancha, thank you for being there for big sister. You guys made me my favourite smoothies and pushed me to go to the gym. You encouraged me throughout this journey. Now I will have time to hang out! You guys are the best brothers in the world and I love you.

Thank you to all my professors at Ryerson University for setting that foundation that I needed so much. 


\section{DEDICATION}

I dedicate this Major Research Paper (MRP) to my mom, Mama Teriano. Although you did not go to school yourself, you made sure I went to school and you fought so hard to make sure I was not married off to become a third wife at a young age. While writing this MRP, I had you in mind all along. I saw your face every time I felt like giving up. I so wanted to make you proud mama. You are my inspiration. You are my Queen. Thank you for instilling in me the desire to follow my dreams. Thank you for teaching me what no one else could ever teach me. I love you Mama! 


\section{TABLE OF CONTENTS}

CHAPTER 1. INTRODUCTION .......................................................................... 1

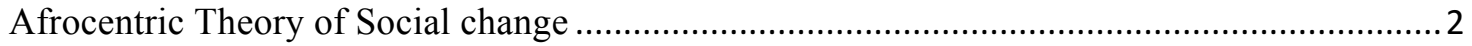

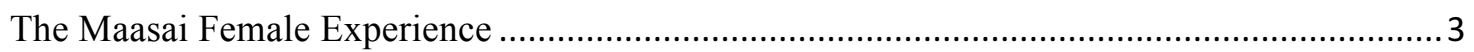

CHAPTER 2. LITERATURE REVIEW ….............................................................. 5

Coloniality of Anti-FGM Discourse, portrayals of Maasai bodies \& its effect on Women ........ 6

Feminism and Racialized Women's Bodies: FGM as a Health Issue .....................................11

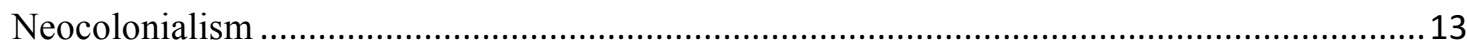

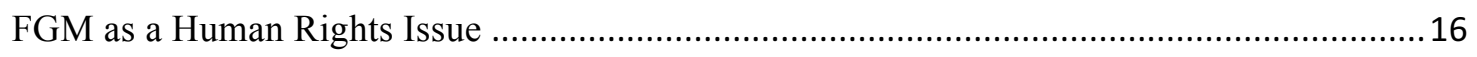

Gaps \& Research Question ......................................................................................... 17

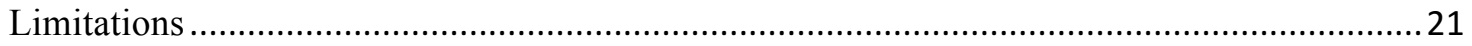

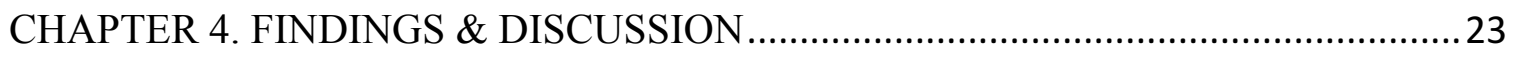

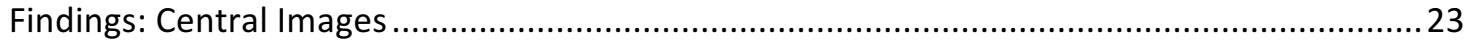

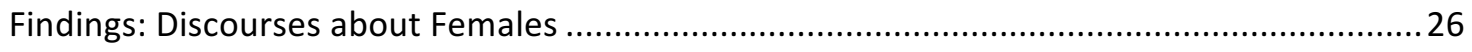

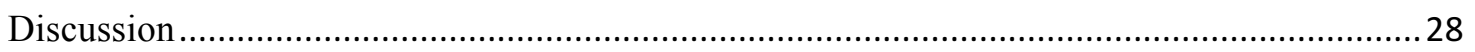

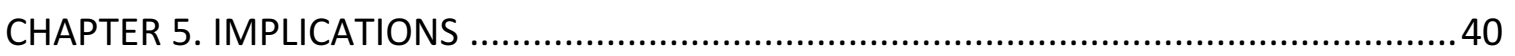

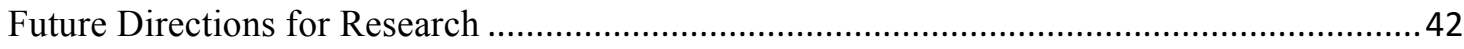

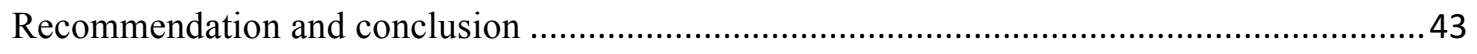

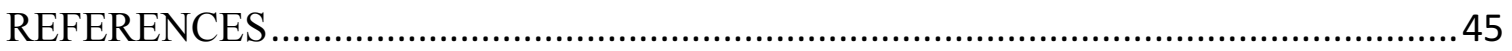




\section{CHAPTER 1. INTRODUCTION}

Female Genital Mutilation is a political global issue and an intimate bodily experience for women who undergo the practice (Irvine, 2011). It brings together medical science, women's health activists, media, national and international policy makers in pursuit of the one goal, eradicating the practice (Njambi, 2004). However, the debate concerning these women is less about the women themselves than about the appropriation of women as political symbols. As argued in this Major Research Paper (MRP), the issue at stake is not the interest of the women rather the consolidation of the powers of others to define those interests. The formation of the anti-FGM movement and the wide reach of powerful discourses that the movement employs, have resulted in FGM becoming an international issue, one that the international community is attempting to address and as an obstruction to development. This position has strong connotations of cultural imperialism. Because of this, African and other non-Western feminists have been reluctant to join the movement even if they themselves are opposed to the practice (Davis, 2004). My approach to this paper is expressed well by Sharon Traweek (1992) who states:

I am going to write some stories for you and I will be in some of them, I want you to know how I came to learn about them and I want you to understand how the stories some of them might be different from what you expect. (p. 432)

As a woman who is: African, Maasai, a community activist and a mature international student pursuing a Masters of Social Work at Ryerson University, I feel privileged to have an opportunity to participate in the knowledge production process through conducting a graduate research project on a topic that is very close to my heart. As a critical social worker researcher currently trained in an anti-oppressive practice approach, I will be situating myself in my MRP 
not only as a researcher but also as a knowledge co-creator and community member of the Maasai Indigenous people. Although throughout this paper I intend to critique the ethnocentrism inherent of anti-FGM discourses, I must make it clear from the beginning that I do not endorse any circumcision practices.

My personal narrative includes the experience of an early arranged marriage. I have participated in working with Maasai girls who do not desire to undergo early marriage. I am also witness to how the NGO agenda has transformed the practice of female circumcision from a cultural practice and using it as assumed evidence of an inherent oppressiveness in Maasai culture. I believe that this has resulted in interventions against female genital mutilation that are colonial, oppressive and objectifying. In responding to this issue, I rely on theoretical lenses that challenge colonialism and revalue the Maasai female experience, as discussed below.

\section{Afrocentric Theory of Social change}

My theoretical framework is based on the Afrocentric theory of social change. This theory is the framework which supports this research work. It is based on the core principle that the African people are not victims, but experts in shaping their own life and reality (Asante, 1993). Afrocentricity suggests that culture shapes and influences the way people think about health, gender, and sexuality (Davis et al., 2010, p.341). This type of analysis produces "indigenous African knowledge that recognizes the African voice while reaffirming the significance of cultural experience as the place to begin to create a dynamic multicultural approach" (Mkabela, 2005, p.184). By grounding this study in an Afrocentric framework, I am seeking to explain the distinctive nature of African culture and how it defines FC. By introducing an Afrocentric theoretical orientation, I am attempting to show the need for a balanced discourse about the traditions that inform African conceptualization of Female circumcision. Furthermore, I see this 
project as a means to break the way in which the African human condition is defined and shaped by dominant Western cultures. My theoretical framework was also informed by understandings about oppression and anti-oppressive practice, particularly those of Mulally (2002). Poole's (2007) work on recovery and public health discourses was also a substantial contributor to my theoretical framework and my understanding of how African female bodies have been objectified in Western media and literature.

Asante defines Afrocentrism as the study of phenomenon, events, ideas and personalities related to Africa and the African diaspora. Asante's (1988) Afrocentric model is particularly beneficial because of its critique of Eurocentric domination. In this case, African people are placed in control of their lives including attitudes about the world (Asante, 1991, p.171). The priority of Afrocentrism lies in placement of African ideals at the center of any analysis involving African culture and behaviour (Asante, 1998, p.2). Afrocentricity questions the centralization of power within a context of whiteness which is aligned to the critical stance assumed by this study and recognizes the role that whiteness plays in socially constructing both the dominant and the oppressed.

\section{The Maasai Female Experience}

In addition to the above noted theoretical lens, in this MRP, I propose a lens that centres the Maasai female experience (MFE), which looks at how Maasai women are seeking to regain their voice and agency stolen from them by a unique intersection of marginalized identities in a capitalist society. I am bringing my own voice to this project by sharing a Maasai Female Experience. The MFE viewpoint stands in agreement with the Afrocentric theory of social change because they both recognize the existing agency of Maasai women and Africans respectively. MFE challenges the notion of victimhood assigned to Maasai women while 
Asante's theory does the same for African people. MFE situates itself alongside Asante's theory in noting that knowledge is not objective but rather shaped by one's culture. These approaches echo cultural relativism in relation to challenging the universalism that is championed by antiFGM discourse. Both approaches seek to reclaim the identities of Maasai women and African people from being shown as inferior. They both also challenge Eurocentric knowledge frameworks for insisting that the knowledge they produce of Maasai women and African people is value-free, objective and accurate.

I have introduced the idea of a unique Maasai Female Experience to address the invisibility and silencing of Maasai women especially in anti-FGM discourse. In the course of my research paper, I found significant gaps in the literature that actually slowed down my progress. Maasai women were rarely objects or subjects of research despite being a significant part of the branding around FGM. This is a unique experience shared by many Maasai women. MFE does not assume to cover all the experiences of all Maasai women. Yet there are a number of identities that intersect in Maasai women's daily lives. As nomads in an agrarian Kenya we are marginalized. As members of the Indigenous rights movement, our land and voice are constantly being disposed. As women, we experience patriarchy in our community, our country and under neocolonialism. As a community that has resisted colonial values, we are marginalized in a Kenya that is obsessed with modernity.

It is my hope that combining my lived experience and the tools of academia to create the term, the Maasai Female Experience, will enable my community to gain and regain visibility, voice and agency in the anti-FGM discourse. I hope that by applying the Afrocentric theory of social change to the Maasai Female Experience that my people will no longer be seen as victims but as owners of their own narratives and destinies. 


\section{CHAPTER 2. LITERATURE REVIEW}

This literature review was conducted with two aims in mind. The first aim was to establish if and how Maasai women were represented in the current academic discourses around the issue of FC. Second, as a Maasai woman who is a knowledge co-creator and community member of the Maasai indigenous people, I wanted to identify gaps and/or misrepresentations of Maasai women in relation to female circumcision that could be addressed in this MRP. To do so, I employed various keywords on a multi-disciplinary database. The multi-disciplinary aspect was key in my literature search, since as I mentioned earlier anti-FGM discourse is directed by people from various fields: health, policy, development, ethics, law, women's rights etc.

I used the following key words: female circumcision, female genital mutilation and 'Maasai' in the title field. This netted 290 results of which 168 were peer-reviewed. Only two results, one of which was a non-peer reviewed publication, Cultural Survival, focused on Maasai women. The other titles focused on: Muslim women, other Kenyan tribes, American history of clitoridectomy and anti-female circumcision interventions. Replacing 'Maasai' with Kenya netted 171 peer-reviewed results out of 297 and 169 peer-reviewed results of 194 . I then did a similar search without specifying the keywords as titles and only found 5 peer-reviewed results for 'Maasai', 4 for 'Kenya' and 3 for 'Tanzania' when associated with 'female circumcision' or 'female genital mutilation'. 'Female circumcision netted 536 peer-reviewed results out of 1142 and 'female genital mutilation' 836 out of 1776 . The timeline for the search was from 1976 to date.

I combined this with a Google search for the term 'Kenya' and examined the first 15 images. For 'female circumcision Kenya', 7 of the first 15 images were of Maasai women or similar tribes that outsiders normally confuse for Maasai--e.g. Rendile, Pokot. For 'FGM 
Kenya', 6 out of 15 images would be understood to be Maasai due to beadwork worn by the women. Key findings from the keyword search in the multi-disciplinary database showed that although Maasai women have been appropriated as symbols by the anti-FGM movement, they are conspicuously invisible and silent in existing academic literature. I experienced considerable difficulty in finding texts written by Maasai women while preparing for this MRP. The Google search was conducted to establish popular and/or discourses around FGM/FC. Searches for 'FGM' or 'female circumcision' did not have Maasai women ranking high in associated image results. However, when the terms were localized to Kenya, Maasai women, as stated before, featured the most prominently. To me, this confirms my experience as a Kenyan Maasai woman. The Maasai woman has become the symbol of female circumcision in Kenya even though other tribes--Gusii, Kikuyu, Nandi, Wardei, etc.--continue to practice it.

\section{Coloniality of Anti-FGM Discourse, portrayals of Maasai bodies \& its effect on Women}

The Kenyan anti-FGM discourse has problematized Maasai culture, making Maasai women doubly marginalized. First, the inherently imperialistic global anti-FGM discourse by forces external to the continent monolithizes African women driven as passive and in need of saving according to Author Njambi. Secondly as a nomadic people in a neocolonialist Kenya, they are further marginalized by the dominant capitalist Kenyan culture that sees their strong cultural attachment as evidence of Maasai primitivity (Nandy, 1988). Ajayi- Soyinka calls this double patriarchy, where current understandings of African women are viewed both through the eye of the colonizer and the colonized who has now internalized colonial ideas. For the Maasai people and woman, colonial agents of knowledge depicted them as being resistant to modernity and primitive. Ashis Nandy argues that modern colonization or neocolonization succeeded by insidiously imposing Western cultural values onto newly independent states (Nandy, 1988). I 
agree with him because the dominant Kenyan national anti-FGM discourse and general narratives of Maasai people and women by extension show them as infantile, weak, passive and in need of rescuing.

This symbolic appropriation of Maasai women as the face of the Kenyan FC campaign further recolonizes Maasai women as their identities and experiences are extracted and commodified by NGOs, policy makers, development entities, the State and the media to acquire funding, gain employment, secure publicity etc. Kenyan dominant narratives in the neocolonial fashion continue to perpetuate the infantilization that Maasai people through a colonial lens that still echoes today. They are judged by the colonial lens, and also by the internalized Eurocentric ideals held by colonized others who perpetuate the colonial idea of native practices as inferior and barbaric; this was an ongoing theme in the articles I examined. Key themes around the antiFGM discourse were the inherent colonialism in its approaches and the construction of female circumcision as a: human rights issue, feminist issue and health concern.

Erasure is inherent in colonialism as seen in the Doctrine of Discovery. It declared that lands unoccupied by Christians were 'terra nullius'; that is, nobody's land as the non-Christian natives were not considered human thereby allowing European monarchies to colonize them (Miller, 2005). Shrubb argues that this erasure of Indigenous peoples, their history and culture is a key trait of colonization (Shrubb, 2004). It is the first way that the anti-FGM discourse recolonizes Maasai women as seen in the absence of, and lack of urgency given to Maasai women's voices in the academic literature on FC. Secondly, historic knowledge production about FC and Maasai women is dominated by external actors and results in erasing the logic, rationale and historicity of why and how Maasai women practice(d) FC. As mentioned before, it was challenging to find information about Maasai women and FC in the academic sphere making 
their bodies a new 'terra nullius' that can be claimed, interpreted and appropriated by whoever wishes to. Colonialism's erasive tendency is echoed in anti-FGM discourse which makes Maasai women the face of FC in Kenya and yet denies them voice.

Academic erasure is colonial and further re-colonizes Maasai women. In the absence of literature specific to the Maasai, I will apply learnings from texts on and/or by other Kenyan women, African women, Women of Colour, Indigenous Peoples and writers of the Global South to demonstrate the inherent imperialism in anti-FGM discourse. My belief is that discourses affecting other colonized or racialized bodies similarly affect Maasai women. Hence I will utilize them to demonstrate the re-colonizing effects of anti-FGM discourses on Maasai women. Key texts include one by Njambi who provides a nuanced first-person account of FGM and exploration of colonial dualism. Ajayi-Soyinka offers a global-south critique of Alice Walker's anti-FGM novel and film. Korie demonstrates the constructedness of FGM and FC.

Njambi (2004) explores how knowledge of African women began with explorer travel monographs and accounts, most of which exaggerated, falsified and deformed African bodies and cultures to confirm to their home countries that yes, Africans were indeed uncivilized and not human. Then the missionaries arrived to humanize the heathens by exposing them their superior Christian faith and Eurocentric knowledge. They were unable to problematize male circumcision as it would show that their biblical traditions were not superior to African traditions. They framed FC as a violation of good Christian morals; they targeted female circumcision as a marker for how 'barbaric' Africans were. Particularly, they focused on the events surrounding Gikuyu FC, where circumcised girls would consort with males of their choice. Instead of employing cultural relativism and understanding the Gikuyu idea of sexuality, they pronounced it promiscuous and sought to eradicate it. Colonial administrators targeted 
circumcision rites for elimination in a bid to erase the group identity to make for easier social control. As a Maasai woman, I can attest that Maasai women experienced the primitivization of their cultures and bodies by anthropologists and missionaries who intentionally or accidentally created inaccuracies about Maasai culture and women that persist today. I find myself constantly having to correct these misconceptions in conversation with other Kenyans, Africans and others. Anti-FGM discourse uses the same language ('barbaric', 'primitive') to describe FC and Maasai women and as such reveals its colonial underpinnings.

The colonial identity and construction of self always exists in a binary opposition to the colonized that creates alterity. Representations of the colonized/colonizer as: self/other, civilized/primitive, cultured/barbaric, modern/backward, human/animal, are replicated by antiFGM conceptual oppositions. These include science/superstition; medical knowledge/tradition; healthy bodies/un-healthy bodies; normal sexuality/abnormal sexuality; civilized/barbaric; modernity/backwardness; expert/non-expert; educated/ignorant, etc. (Njambi, 2004). This colonial identity always places the colonized as different in order to create a narrative where the colonial intervention is necessary for the well-being of the colonized. The colonizer justifies the erasure and marginalization of colonized voices by assuming they know what is best. The antiFGM movement perpetuates this Othering of the bodies of African women by situating themselves as 'emancipated Western women' aiding the 'oppressed backward non-Western women' (Korie, 2005). Even a distant relative of the African woman, African-American author Alice Walker perpetuates Othering of other racialized bodies by undermining practitioners of the rite in Senegal and Gambia in her film Warrior Marks. The dichotomous colonial worldview differs from my experience as a Maasai woman whose sense of self is tied to the collective. The Othering language employed in anti-FGM language, has led to Maasai Women who subscribe to 
it experiencing the double consciousness of W.E.B. Du Bois where they are forced to see themselves through the eyes of Others. Maasai womens' whole selves are fragmented and distilled down only to their sexual parts in anti-FGM. Their complexities that defy Eurocentric binary notions are ignored and focus is put on their sexual organs as a battleground for state agents, development entities, feminists, anti-FGM campaigners, etc. Asylum seekers who base their appeals on escaping FC in their home countries end up being used to perpetuate this alterity. One Nigerian lawyer in an American court phrased FGM as a "brutal...ritual that violates...notions of decency and civilization at the heart of this Republic" (cited in Gunning, 1992). Gunning argues that legal proceedings are a neocolonial continuation of imperialism where America now replaces European colonizers and continues the task of defining itself as the norm and other countries and cultures as unevolved deviations from the norm (Gunning, 1992).

Historically female bodies have been colonial battlefields as seen in the rapes of Kenyan women by British colonial soldiers (Njambi, 2004). Racialized bodies have also been colonial battlefields as seen in the policing of cultural clothing of both colonized natives and slaves. The Gikuyu experience under colonialism can be extended to Maasai women as the two Kenyan communities border one another, have ongoing albeit different anti-FGM narratives; and share similar accounts of resistance to the British colonizers. Njambi notes that for the Gikuyu both the colonized and colonizer emerged from two patriarchal systems and women were reconstructed as war landscapes between the two. Colonialists used religious and cultural superiority to frame FC as evidence of native barbarism and ungodliness. Jomo Kenyatta, a major Gikuyu resistor and Kenya's first president engaged in the post-colonial exercise of reclaiming Gikuyu history and culture from the margins by writing Facing Mount Kenya (Kenyatta, 1959). In it, as a Gikuyu political and cultural leader, he denounced colonial undermining of Kikuyu Indigenous values, 
advocated for FC to continue and insisted that Kikuyu man should marry an uncircumcised woman. Women's traditional roles as cultural custodians took on more nationalistic tones. FC became a way to rebuild community identity after colonial attacks.

\section{Feminism and Racialized Women's Bodies: FGM as a Health Issue}

The World Health Organization (WHO) taxonomy has existed since 2008. Type 1, referred to as clitoridectomy is the partial or total removal of the clitoris and occasionally the prepuce. Type 2, as excision is the partial or total removal of the clitoris and the labia minora (the inner folds of the vulva), with or without excision of the labia majora (the outer folds of skin of the vulva). Type 3 , referred to o as infibulation is the narrowing of the vaginal opening by cutting and repositioning the labia minora, or labia majora, sometimes through stitching, with or without removal of the clitoris. Type 4 includes all other harmful procedures to the female genitalia for non-medical purposes, e.g. pricking, piercing, incising, scraping and cauterizing the genital area (WHO, 2017). This taxonomy is less loaded with Western cultural values as it relies on numbers rather than cultural and evocative terms like Sunna, infibulation etc. It is telling that anti-FGM discourse continues to use an old model. I would argue because this old taxonomy allows for evocative language that monopolizes and Others communities that practice FC.

Njambi uses embodiment theory to argue that the body is the site of enculturation and acculturation. As such anti-FGM campaigners cannot assume Maasai women's bodies are just biological entities on which they can project Western values. They are attached to their 'local specificities and variations" and cannot be completely understood outside their cultural context. I agree with her caution to anti-FGM voices to not replicate the Western view of a 'natural body' and to understand that no knowledge is absolutely objective. She asks how anti-FGM discourse perpetuates and supports forms of violence and silencing. From my own local specificity as a 
Maasai woman, I can answer that anti-FGM discourse wreaks physical violence on Maasai women's bodies as they are sometimes attacked by those around them when they attempt to resist anti-FGM. It also is emotionally and psychologically violent as it depicts them as inferior, passive, and robs them of their voice.

The double standards seen in anti-FGM discourse points to another colonial mindset where the same action receives different meanings depending on who does it. If a Westerner does it, it is contextualized to legitimate it whereas if a racialized person does it, it is isolated and stereotyped as deviant. Anti-FGM campaigners castigate Global South cultures that engage in FC. Yet, they will not challenge the rising Western popularity of similar genital modifications. Labioplasty, a reduction or removal of the labia minora for aesthetic reasons and clitoral hood removal are similar to clitoridectomy. Vaginal rejuvenation, the removal and/or sewing of vaginal tissue to tighten the vaginal canal and is arguably similar to the tightening that happens during infibulation. Western and indigenous body modification practices are fuelled by the desire to be perceived as attractive and are therefore intended to satisfy the male gaze (Albutt, 1896). Instead of using this shared burden as a place to begin allyships with women affected by FC, anti-FGM discourse conveniently mutes this double standard.

The colonial erasure and double standards are entrenched into colonialism. Anti-FGM discourse has conveniently ignored the fact that clitoridectomy was used in Britain and the US as late as the 1940s to cure emotional disorders as seen in an early gynecology textbook that stated it might be necessary to amputate the clitoris (Albutt, 1896). Again, instead of using this information to equalize the discourse with women from the Global South and globalize the narrative of FGM, anti-FGM voices have been quiet on this shared history of FC. This is because 
it helps them maintain their colonial superiority where they can tell inferior and ignorant global south women that FC is a problem and how to fix it.

Fran Hosken is a good example of this colonial benefitting from the objectification of women's bodies via FGM messaging. In 1993, this Harvard-trained art designer turned women's activist published the Hosken Report: Genital and Sexual Mutilation of Females. She coined the term Female Genital Mutilation as she felt FC did not adequately evoke the horror she wanted in her audience. Her obituary states that she ignored accusations by anthropologists of committing cultural genocide by criticizing Africans for countenancing female circumcision (Hosken, 1993). This shows that the anti-FGM movement was birthed out of a colonial mentality that saw African cultures as unworthy of respect. This has carried on today where Maasai women are not respected enough to be given voice and agency to decide if and how they want to address FC. Hosken's choice to use the word 'mutilation' instead of circumcision is a return to the colonial Othering of racialized and gendered bodies by showing their culture as barbaric, violent and primitive. By naming the report after herself, she positions herself as an expert and takes the voice of all the women affected. It is unfortunate that almost all the sources I saw quoted the Hosken report as a reliable expert source on FGM. In doing so, the current academic literature continues to give space to the imperialistic voice of modern feminism and thereby recolonizes Maasai women by not involving them in the knowledge creation process of creating or revising the anti-FGM narrative.

\section{Neocolonialism}

The medical world is not exempt from colonial attitudes which create a false norm based on Eurocentric values. Njambi (2004) describes how medical textbooks typically depict white male bodies as the standard which further perpetuates the colonial positioning of the white male 
as the universalized normal body. This also means Maasai female bodies are doubly deviant from this norm due to their sex and race recalling Ajayi-Soyinka's double patriarchy. Njambi further notes that penises in these texts are normally circumcised. If male circumcision is the medical norm, then FC practices that simply remove the clitoral hood (foreskin) should also be normalized. Walker and other feminists have been criticized for using Eurocentric lenses to see the circumcised body as a distortion of an original perfect body. By normalizing white bodies, anti-FGM campaigners can hypocritically normalize labioplasty and vaginal rejuvenation where modifications are made to a woman's genitals because they happen in the West but codify FC as deviant, barbaric and primitive. This universalizing of the white male body in medicine recolonizes Maasai women as they are cast as deviant by sex and race.

The colonial agenda conflates distinct cultures and peoples into a monolith creating the binary of ruler/empire and colonizer/natives. Anti-FGM lore similarly ignores how each tribe is different in its enactment of FC and conflates it all under the term of FGM. Current FGM taxonomy is sunna (removal of prepuce), clitoridectomy (cutting of clitoris and/or removal or cutting of labia minora) and infibulation where clitoris, labia majora and minora are removed and sometimes sewing is done leaving only a small space for urination (Ajayi, 1993). Njambi (2004) notes that this taxonomy does not reflect all the different particularities of the practice on the continent. She critiques the fact that this taxonomy is replicated in text after text without being revised and questioned. This is because This Western creation that generalizes a practice over hundreds of particular cultures has now become the standard frame of FC. To make matters worse, due to anti-FGM discourse, infibulation has become the key messaging of what FC is in the Western World. By continuing the tendency to generalize the unique cultural practices of the formerly colonized into one entity of a primitive custom, anti-FGM discourse engages in 
recolonizing women of the Global South, and by extension Maasai women. It is interesting that in Kenya, Somali and Maasai women are the most identified with FC even though over 32 tribes practice it. A 2016 publication by anti-FGM organization, 28 Too Many, features three Maasai girls on the cover, no Maasai women on the publication team and its executive summary states that Maasais rank third behind Somalis and Samburus for prevalence of FGM. This is upsetting proof of how Maasai women have been appropriated as symbols of a cultural practice that is global in nature and yet their voices are not at the decision or knowledge production tables that surround the anti-FGM campaign. It further continues the paternalistic colonial mindset in Kipling's White Man's Burden that assumes it knows what is best for its 'half-child half-devil' peoples (Kipling, 1956).

Similarly for Maasai women, their bodies are the battleground for cultural identity and neo-colonial values. The fight of Western education, female sexual enjoyment and capitalism, against Maasai knowledge, female morality and collectivism happens on the bodies of Maasai women. I remember seeing older women not being allowed to wear their beadwork to church since Maasai culture was seen as opposite to Christianity. The bodies of Maasai women have become the subject of erroneous myths that are perpetuated in Kenya--e.g. Maasai can share wives if they plant a rungu in front of their friend's hut. Anti-FGM discourse has made Maasai women the symbol of FGM even though in their own publications, anti-FGM campaigners admit that Maasai do not use infibulation (Gatens, 1996). They utilize Maasai women make their bodies as battle ground for all FC practices even those that do not concern them.

How did colonialism benefit from the anti-FGM discourse? The loss of circumcision rites lessened group cohesion. This enabled colonialists to increase their power and enculturation. Similarly, anti-FGM discourse splits the Maasai community making it more 
susceptible to further marginalization in Kenyan society. This enables it to increase its control of the identities of the racialized women similar to colonization. It echoes the extractive colonial state that takes resources from the global south to the home state. It has created an industrial complex where the bodies and minds of Maasai women and other racialized women are commodified. Activists have used these commodified Maasai women bodies to create their own careers, reputations, get funding and get publicity.

\section{FGM as a Human Rights Issue}

Further to recolonizing Maasai women by presenting their culture as barbaric and primitive is the biased definition of FC versus genital surgery for cosmetic purposes. These two practices that may appear to be intrinsically different, having originated from different premises, may in fact share more commonalities than differences. Neither surgeries are performed for medically justifiable reasons, but FC is Othered on the premise of consent not being obtained. Krivenko (2015) describes the discourse of human rights' knowledge on FC as "hegemonizing, racializing, and discriminatory”. She seeks to challenge whether the international community would still call for prohibition of FC, if a woman desires this surgery for aesthetic and well-being purposes. The biased and racialized response of the international community on FC is not always honest and fair, requiring an urgent re-evaluation of the way these practices are addressed.

Rethinking the approach to FC needs to be informed by rediscovering research in interdisciplinary (medical science and anthropology) sources of multidimensional and informed knowledge, otherwise human rights will remain subject to criticism of imperialist and colonizing attitudes. When examining FC and genital cosmetic surgeries, the overlapping nature of both surgeries suggests that the final outcome is to alter genitalia via surgery as a means of improvement depending on the subjective definition in both instances. Krivenko (2015) has 
noted that when FC is described by the World Health Organization, terminology such as "excision, "removal", "cutting", and "harmful" are used; compared to medical practitioners describing Western surgeries as "augmentation", "reduction", "rejuvenation”, and "amplification" when describing cosmetic surgery, implying the latter form of modification is achieved without "cutting."

\section{Gaps \& Research Question}

As noted earlier, the existing literature shows that there is very limited research into establishing the effectiveness of anti-FGM interventions in the Maasai community. It also shows the need to have more narratives of the Maasai Female Experience (MFE) produced by Maasai women themselves. To fill this knowledge gap, my MRP will aim to put focus on privileging the often-silenced voices of Maasai Indigenous women through an exploration of discourses that attempt to silence them. Specifically, I ask the following question: How do the discourses of Western NGOs active on FC reproduce colonialism? 


\section{CHAPTER 3. METHODOLOGY}

I chose critical discourse analysis as my research methodology because I am exploring how the NGO discourse in the anti-FGM campaigns is colonizing Maasai women. My reason for choosing critical discourse analysis as a methodology was to study the structures that control the anti-FGM campaigns in the Maasai community; these campaigns are driven by international NGOs. Critical discourse analysis is the study of how discourses of power and dominance are reproduced in society and inversely, how these discourses are challenged and resisted (van Dijk, 1993; Wodak \& Meyer, 2014). Critical discourse analysts take clear socio-political stances to analyze texts with the aim of uncovering the discourses that affect oppressed people (van Dijk, 1993). I chose this methodology because I am interested on how this discourse is constructed by the NGOs that carry out the anti-FGM campaigns.

In my MRP I will be using Poole (2007)'s critical discourse analysis methodology, which takes its inspiration from Fairclough $(1989,1992)$ and Jaeger (2002). I chose Poole's methodology because of the clarity of her methodology and her focus on the social problem of recovery. Just as Poole conducted a critical discourse analysis to understand discourses associated with this problem, I wanted to examine discourses associated with the problem of anti-FGM campaigns driven by International NGOs in the Maasai community.

In her summary of her methodology, Poole (2007) described her first step as focus on a specific social problem. Inspired by Poole (2007), I identified the topic of anti FGM, specifically discourses about Maasai women and discourses about anti-FGM campaigns and the discrimination of Maasai women, as my topic of study. To begin I conducted an extensive literature review of academic literature about the anti-FGM campaigns.

Discourses are constructed by the world but also construct the world (Fairclough, 2003; 
Wodak \& Meyer, 2009). Critical discourse analysis sees discourses as being produced and influenced by power and ideology and understands prevailing social orders as being sustained and constituted through the effects of discourses (van Dijk, 1993; Wodak \& Meyer, 2009). It sees discourses of power and dominance as creating society and inversely also examines how discourses are challenged and resisted (van Dijk, 1993; Wodak \& Meyer, 2014). Critical discourse analysts take clear socio-political stances to analyze texts with the aim of uncovering the discourses that affect oppressed populations (van Dijk, 1993).

In her discussion of her methodology, Poole (2007) drew on Wodak and Meyer's (2002) summary of Fairclough's critical discourse methodology. According to them, one step in Fairclough's version of critical discourse analysis is to "identify the dominant styles, genres, discourses constituting" the problem being studied (Wodak \& Meyer, 2002, p. 28). Critical discourse analysts must also "Identity the resistance against the colonialization processes executed by the dominant styles, genres and discourses (Wodak \& Meyer, 2002, p. 28). Poole also cited Fairclough's admonishment that discourse analysts must study discourses at an intertextual level by comparing both resistant and dominant discourses.

To conduct critical discourse analysis as outlined by Poole (2007), I chose to look at AMREF Africa as an example of an international NGO in the anti-FGM campaigns frontline. I chose AMREF because it is the most active NGO addressing this issue in the Maasai community in Kenya. My text analyzed in this MRP is the documentary produced by the Kenyan Nation Media Televsion (NTV) and AMREF Africa. The documentary, the The Anti-Cut Warriors of the Maasai Community, was aired in 2016. I chose the documentary published by NTV because NTV is one of the most watched television stations in Kenya. 
According to Mullaly (2002) news media agencies like NTV Kenya, as part of mass media, are a mechanism for the reproduction and reconstitution of the "dominant cultural messages, images or products" of society (p. 98). News media agencies create, distribute and reproduce images that represent dominant group members as the norm and also identify subjects and topics as newsworthy. This newsworthiness is based on the economic, political, cultural, and social ideologies upheld by these companies. This then contributes to the institutionalization of power and dominance for these dominant group members (van Dijk, 1993)

I see this MRP as a perfect space to begin to push back and challenge discourses constructed by anti-FGM campaigns that are assumed as well as a way to combat silences on this issue in social work that I believe are indicative of wider social discourses that influence the way we think. I watched the documentary; the The Anti-Cut Warriors of the Maasai Community several times and paid attention to recurring themes and images as well as the body language of the characters and that of the narrator. I also paid attention to the background and the dress code of the characters.

I drew heavily on Poole's (2007) method of data analysis, first examining the video for themes, images and body language that stood out. I made lots of notes while watching. I had to watch it a few times as it was very hard to watch. Throughout, I constantly brought my awareness back to my reactions, and made lots of notes as I was watching. I am aware that I have a particular set of counter-discourses about anti-FGM narratives that inform my theoretical framework as a Maasai woman. Part of being critical about my place in this research was to not jump to the hard conclusion that mass media would universally demonize Maasai, African women. I constantly reminded myself to stay mindful, open, and welcoming to refutations and surprises in the film (Poole, 2007). I wanted to focus on how close the documentary was to my 
definition of discourse, but I also wanted to make note of the ways in which it deviated.

Discourses have rules, and in the discussion section I will be transparent not only about where I discovered rules in dominant discourses, but where the film triggered a reaction in me because it was transgressing my discursive rules.

I had several ethical considerations when conceptualizing this research. I was concerned about potential risks for myself and others. Watching the film could be judgemental or problematic in many ways and could bring up issues for me as a Maasai woman. It is difficult for me personally because I am part of this community and I have to come face-to-face with societally accepted negativity towards this issue. I chose to use those moments of discomfort as learning opportunities. I critically reflected on why I was feeling uncomfortable, what was causing my reaction and why it was important for my research. I elaborate more on those moments in the Discussion section, because it is important for me not to present myself as an objective researcher who was somehow removed from the data.

Everything about my reactions guided my analysis. I also considered the risks to potential future readers of my MRP. It might be difficult for a Maasai woman to read it, just as the documentary was difficult for me to watch. It also might be difficult for other Black women to read it and be faced with the reality about the colonial and racist treatment of Black female bodies. I hope that the readers who do seek out my MRP understand the potential discomfort they may experience, and do what is best for them, including not continuing to read it.

\section{Limitations}

My research design had some limitations. The main limitation is that my sample was only the NTV documentary. This narrow focus means that I cannot draw broader conclusions about anti-FGM campaigns discourses and how they are operating in the Maasai community. I can 
draw conclusions about how the mainstream media is presenting and upholding these discourses, but this is only one kind of media. I also looked at AMREF Africa as an example of all International NGOs involved in the anti-FGM campaigns. While there is a lot of similarity in how NGOs engage on this issue, AMREF Africa is only one NGO.

Another limitation was that I did not look at a larger number of news articles or documentaries from a broader timeframe. This research is a very small snapshot of a much larger picture. For example, I would have preferred to select articles from the past 10 years and from different NGOs. However, with the time constraints, I felt I could not reasonably analyze more data within this timeframe. I also feel that a limitation of my MRP was my own inexperience as a researcher.

I almost regret choosing discourse analysis as my methodology and I considered changing it but it was not possible with the time frame. It would have been easier to select a methodology where the steps to conducting research were much more clearly laid out. I was and I am uncomfortable with having the research be so completely guided by my own interpretations and impressions, because I felt a lot of uncertainty about the process. It was extremely difficult to unpack notions of the researcher as an expert, even within our anti-oppressive Master's program. I struggled with feelings of inadequacy as a researcher throughout the entire process. I tried to at least be transparent about my moments of uncertainty and to do ongoing work focusing on becoming comfortable with the idea that I was not in any sort an expert. 


\section{CHAPTER 4. FINDINGS \& DISCUSSION}

In this chapter, I will outline the findings from my analysis of the documentary: The AntiCut Warriors of the Maasai Community produced by NTV Kenya (NTV, 2016). The documentary yielded some discourses that support the construction of anti-FGM campaigns that are influenced by certain power relations. The main discourses evident in the film are; saving the Maasai girl, changing the culture and double patriarchy. Also, the images in the film are very powerful and play into the stereotype of Maasai culture as a primitive culture that is ignorant and one that women need to be saved from.

\section{Findings: Central Images}

The first thing that stood out in the film were the images. The men and the women in the film were all dressed in traditional clothes that are not everyday clothes but those that are worn to special ceremonies. This to me meant that this documentary did not capture the daily life of Maasai people. It shows me that this was a staged documentary, that the participants were encouraged to wear traditional outfits instead of their normal outfits that are a mix of modern and traditional clothes. This to me shows that the producers of the documentary wanted the traditional clothes to continue branding the discourse around Maasai women as a clash between modern and primitive values. If they had let the participants wear what they would normally wear that binary of modern versus primitive would have been difficult to sell to the audience.

The film starts off with the image of a Maasai woman outside a traditional Maasai hut. The chief Moran who is also the main character in the film walks out of one of the Maasai traditional huts. The warriors in the film are dressed in traditional attire although they are speaking Swahili. Because I come from this community, I am aware that warriors would not normally speak English or Swahili because they did not go to school. The documentary was shot 
in the Maasai village of Olkiramatian. I have been in this place and I have relatives that still live there.

There are also images of tools used to carry out FC. The topic of FC is introduced in the documentary by the image of a razor blade with the inscription: "anti-cut warriors" (Kenya, 2016, 2:07/23:07). The razor blade is the tool used to carry out FC. The voices of the warriors can be heard singing in the background while the image of the tool is displayed on the television screen. Ole Lein Kanunga, the group's leader also known as the Chief Moran in the film is also dressed in traditional clothing. Ole Kanunga speaks Swahili in the film instead of Maa, the Indigenous language spoken by the Maasai peoples. At (3:25/23:07) we see images of the tools that are used to carry out FC. It is displayed on the screen for some time while the narrator continues to speak about FC being an old age tradition that has been hard to fight.

At 3:32/23:7, we are shown an image of an elderly Maasai woman's pierced ear and a girl who is seen walking in the forest (Kenya, 2016). There are also images of the chief Moran educating girls and other men about the effects of FC. They are typically sitting under a tree 5:00/23:7. Images of men singing in the bush are displayed while the narrator talks about the rich culture and the bright colours. When the chief Moran is talking about girls, the camera focuses on the girls. They stare back in a quiet silence. The chief Moran, ole Kanunga is seen (13:03/23:07) joining a group of community members. He speaks to them in Swahili about eradicating FC. Everyone seems to agree with him. The women are given a chance to speak at this point and they stand in agreement with the Moran. They express how they do not support the practice even though they have undergone the procedure in their younger days. They are all dressed in traditional attire. The camera when not focused on Kanunga is showing images of the women and girls. 
As stated before, women's bodies consistently appear in the film. The opening scene is of a Maasai woman dressed in traditional clothes standing next to a enkaji (traditional Maasai living structure). In the ending scene of the documentary the camera runs through images of various women and girls. It shows their faces and then rests on a group of women sitting in a field on plastic chairs. These images are accompanied by Kanunga speaking of his personal fight to see his vision come true. His vision being the end of FC and to see the girls educated. The documentary ends where a group of Maasai morans are heard singing, the camera focuses on the group of women sitting on plastic chairs while the narrator says "Whether long lasting changes can be made in the wider Maasai community is uncertain but the impetus for change has begun." This use of the bodies of Maasai women as visual props to tell the story of Kanunga's conversion to anti-FGM campaigner and the story of AMREF as an organization is highly problematic, as I discuss later in this chapter.

The documentary itself is full of aspects that are problematic. Due to the limits of space, I have chosen a few to focus on the aspects that are most related to the idea of the specificity of the Maasai Female Experience. Part of the Maasai Female Experience concept seeks to place Maasai women as the authors, articulators and definers of their own social identity since dominant sociopolitical discourses render them invisible both on the Kenyan landscape and on the global scene. I will therefore focus on aspects where this documentary as a representative text of the anti-FGM discourse recreates colonial, neocolonial and patriarchal understandings of Maasai women and their bodies and denies them voice and agency. 


\section{Findings: Discourses about Females}

\section{Girls'education}

In this film, a lot of emphasis is put on the importance of Western education for girls. The men assert that the act of cutting is a deterrent to the advancement and achievement of success. During a meeting with the elders, it is acknowledged that circumcising girls is a much more invasive procedure that mutilates and damages not just the physical, but the mental health of a young woman. It is mentioned that girls who undergo cutting eventually drop out of school due to lack of motivation and ambition. Cutting of the girl child expedites the gradual process of growth stages, by forcing the young girl to assume the role of a wife or mother too early.

According to one of the elders, the girl "feels mature and becomes stubborn, and her performance drops drastically" due to the assumption that she has come of age and no longer needs guidance, especially as it pertains to her education. The girl child proceeds to drop out of school, denying herself the opportunity of becoming a successful and productive member of her community. Kanunga also expresses the loss of the community as a whole when potential "doctors, pilots, and teachers" are not realized. The elder goes on to discuss the cost of hosting a post cutting ceremony: "four cows and twenty goats are slaughtered for merry making". He implores the community to focus on a different kind of celebration: celebrating the girl child's achievement during graduation. Let us "stop cutting our girls and educate them to university level education."

Throughout the documentary, different prepubescent and adolescent girls appear on screen. Often, they appear to be in deep thought. They all have no dialogue in the film. The only time their voices are heard is at the end of the film. They sing a song "washa moto ya elimu, 
zima moto ya tohora." When translated to English this means light the fire of education and put off the fire of circumcision.

\section{Other female figures}

The Kenyan first lady, Mrs Margret Kenyatta is seen in the film attending a ceremony in Olkiramatian village to celebrate the efforts of the Anti-Cut Warriors. During her appearance, her speech endorsed the message of eradicating FC stating: "Denouncing FC, led by the council of elders is a remarkable turning point for this community." She praised the warriors for their bravery in addressing this sensitive topic in their community but makes no mention of the women who are affected or who undertake this practice.

The reporter, Rose Wangui is a Kenyan woman. She is mostly off-camera and is only seen twice. Once when she is sitting down with Kanunga to discuss his role as the leader of the anti-cut warrior group and another time sitting with all the men. The morans say they have chosen to marry the girls who are not circumcised as a way to end FC.

\section{Culture}

It is discussed in the film that FGM is an old tradition that has been around for ages. Kanunga explains how he had a difficult time introducing the conversation about FC to the community after his training by AMREF as a peer educator. He had a difficult time explaining because this is a long standing cultural practice in the Maasai community. He also reveals that his mother and grandmothers went through the practice. He talks about when he first introduced the topic of eradicating FGM in the village it was not well received. Being a young man, 27 years old, he was afraid that he would be seen as misleading the community since the elders never addressed the issue. He said what motivated him was the fact that FGM was never 
mentioned in the bible. He got the courage through the bible to speak to the community to end FGM. He said he will change the culture to fight for the right of the girl child.

Although the film is about women, particularly women's bodies, the only voice that is heard throughout the film is that of the men. The men in the film are very confident and outspoken while the women are silent. We often see the image of a Maasai girl when the chief Moran or the narrator is discussing FGM. The girl image is shown but she is silent and looks innocent. The chief Moran speaks about how men make decisions in the community and how each Moran (warrior) has a role to play. It is all about the man. "Once a girl is circumcised she feels mature and can be stubborn, even if she's in school, her performance drops drastically." One of the men said in the film (10:05/23:07).

\section{Discussion}

The discourses operating in the film were powerful and very well-constructed. Here, I question some of the assumed truths, and discuss what this means for community development workers, social workers and health workers. Throughout the discussion, I do not presume to know the individual intentions of the warriors as I believe such workers find themselves in situations where their own choices are dictated not exclusively by themselves (Wehbi \& Taylor, 2012). As such, in this MRP, I focus on the international NGOs discourse that drives and control the anti-FGM movement in the Maasai community.

Wehbi \& Taylor (2012) stated that what makes the medium of photography so potentially powerful in community development work is it reflects and perpetuate neo-colonial discourses that serve the purpose of recurring imperialist agendas. It is important to note that the first imagery the West had of Africa was based on travelogues from European explorers who grossly 
exaggerated and misrepresented the people of the continent. These travelogues depicted Africans more like animals than humans who needed to be saved from themselves.

The next iteration of images regarding Africans were photographs taken by anthropologists and colonialists where Africans dressed in their traditional costumes were photographed and their pictures were distributed widely without the Africans' informed consent. These images were rarely contextualized in a way that showed the rationality and logic behind the natives' costumes or cultural practices. Instead they were used to show how backward and primitive the natives were in comparison to the white colonialists who had taken upon themselves Kipling's white man's burden of civilizing the uncivilized hordes of the world. These photographs continue to fill magazines like the National Geographic where the photograph of one lone Indigenous African in their native wear serves to represent an entire continent that is peopled by thousands of different languages, customs and tribes.

The fact that the producers of the documentary ensured that all the interviewees were wearing traditional clothing enabled the continuation of the view of the Maasai as a primitive people who still need help to catch up with modernity. This is neocolonialism at its finest. The colonized internalize the colonizer's perception and apply it to each other. In this case, the Kenyan reporter is from another tribe that has historically considered itself superior to other Kenyan tribes. This hierarchy of the oppressed can be found in every country that has a colonial past. Colonizers identified various groups as being more suitable to assist in the colonial task. These groups assumed the power and superior position of the colonizers once these countries got their independence and continued to perpetuate the oppression of the colonizer on their brothers. This reporter having internalized the colonial view that the Maasai are primitive ensures that they 
are dressed in traditional clothing in order to show how they are still primitive in continuing FC instead of abandoning it in favor of modernity.

This neocolonialist discourse affects women even more disproportionately than men in the Maasai community. The double patriarchy from the Maasai community and the inherent paternalism of neo-colonialism means Maasai women are used as tools to further the goals of NGOs like AMREF and the goals of the men in their community. Maasai women are positioned as primitive and childlike in need of saving. Once again in this documentary we see that Maasai women are made the face of the practice of FC but are denied their voice. This is the intersectionality of oppressions that the Maasai Female Experience seeks to describe and critique.

I personally can attest to how Maasai attire has been used further that discourse of modernity versus primitivity that marks the Maasai Female Experience. Often when doing media presentations or speaking engagements, I have been asked to ensure that I am wearing traditional Maasai attire. Whenever I have pushed back, most organizers are unable to give me a cogent reason for me to wear the attire other than it makes my story more 'impactful'. That 'impactfulness' that these organizers are referring to is because the repeated mediated representation of Maasai culture via its traditional attire has created a singular monothilized representation of Maasai people. This mediated representation is so powerful that audiences believe that any other different representation of Maasai bodies is inauthentic. This means that for my reality as a Maasai woman in North America who wears jeans daily is discounted because it does not confirm the representation that Western audiences have been taught to expect via imperialism, colonialism and neocolonialism. It means that my voice and the voices of the Maasai girls and women in the film are not respected or heard unless they confirm what the 
audiences already think they know: that Maasai women are primitive and need to be saved from FC. The women in the documentary and myself undergo the Maasai Female Experience of having others dictate over our bodies.

\section{Double Patriarchy}

As a Maasai woman, I found this documentary to be problematic. I am aware of the struggles, discrimination and oppression faced by women in the Maasai community. Watching them being silenced and have the men speak on their behalf about an issue concerning their bodies reminds me of my life growing up. I am reminded of the Maasai traditional sayings about women and girls which always described women as weaker and less than the boys and men. I will give an example of two of the many "wise" sayings "Meeta olee olkiti"--in English "there is no young/small man"--meaning as long as someone is a man even if they are younger or smaller than the woman they are still better in every way: braver, smarter, wiser, etc. Another saying “dorrop osina lenkaji natii olayioni"--in English, "poverty is short in a family that has a son"-meaning if a family has a son even if they are poor now, they will soon be rich. Because of beliefs like this one, the birth of a son is more valued than that of a girl. When a son is born a bull is slaughtered whereas when a girl is born a sheep is slaughtered. I grew up hearing this and many other sayings. They had a negative impact on my life. I had to unlearn these beliefs in order to believe that as a woman I am just as capable.

The Maasai culture is imbued with patriarchy; watching the film, I see what AjayiSoyinka (1993) calls double patriarchy where current understandings of African women are viewed both through the eye of the colonizer and the colonized who has now internalized colonial ideas. While the film is packaged as a good cause for women's rights, it is more damaging than helpful to Maasai women. First, their voices are missing from the audio of the 
film. The film consists mostly of Kanunga sharing his personal story and philosophy. There is not even a token attempt to pretend to give women a voice. The very absence of this tokenism shows the degree to which this patriarchy is so embedded in Maasai culture that even the women do not appear interested in fighting for a voice. This patriarchy is then continued by the neocolonial attitude of the reporter who does not appear to see the journalistic imperative to include the voices of those most affected by the issue she is covering. I am not saying that it is wrong for men to fight for the rights of women but at the end of the day if one is fighting for the rights of someone, can you at least consult with them?

FC is a multi-facted practice and as such must be addressed by involving all sectors of the community. The documentary is focused on these warriors who have taken the unusual step of denouncing FGM. Understandably a majority of the dialogue or screen time would go to these warriors. However, a well-rounded documentary must always include other voices and other people affected by the topic under discussion. Basic good journalism means that the content creator needs to include opposing views in order to give a nuanced understanding to the audience. Basic good journalism means that an issue is explored across various demographics. On the basis of good journalism and good documentary-making, I would expect the documentary makers to give voice to the women in order to hear their views on these Anti-Cut Warriors at the very minimum. This documentary continues the violent silencing of Maasai women by patriarchal Maasai culture by showing that their voices are not needed even on a topic that affects their very bodies.

Who benefits from this?

I agree with Razack (2006) who states that the paradigm of saving the other precludes an examination of how this has contributed to the crisis of Global South countries. This paradigm 
allows the North to maintain its own sense of superiority. The Maasai girl has become a marketing object for NGOs looking for funding to further their colonial agenda. As a Maasai woman, I am aware that majority of people from my community do not have access to electricity and do not own televisions. While watching the documentary I wondered, if the purpose of this film was ostensibly a campaign to stop FGM in the Maasai community, why is this story aired on national television yet the people concerned (the Maasai) cannot even watch it or understand the language being spoken? The majority of the people supporting FGM in the Maasai community are the older generation who do not have a Western education and therefore do not speak English or Swahili. I presume this documentary was made for the donor community, the institutions that keep these discourses alive through funding them.

Since these International NGOs get their funding from the North, they are able to maintain their superiority and further their colonial agenda through these Organizations (Razack, 2004). The Maasai girl in the film is silenced and is used as a tool to raise money to "save" her from her "primitive" culture. Njambi (2004) states that the anti-FGM have created this narrative that African women are passive and need saving. In this case, the NGO benefits from the anti-cut warriors' story of eradicating FGM and the Maasai girl continue to be marginalized both in her own community, in Kenyan society, as well in the global community as a Black woman. These levels of oppression intersect and put the Maasai woman in a very vulnerable state. The NGOs, with its emphasis on pity and compassion, saving the other, can be a position that discourages respect and true beliefs in the personhood of others (Razack, 2004).

While I believe girls' education is important and a lot of emphasis has been put on this in the film, I do not agree that women who go through FC cannot excel in school. There are too many other barriers other than FC that are hindering Maasai girls from achieving an education; 
for example, poverty and arranged marriage which are not addressed in the documentary. Most Maasai girls drop out of school because their parents cannot afford tuition or because they are forced into marriage. As mentioned earlier, part of my personal experience is that of an arranged marriage. NGOs chose to focus only on one particular issue while there are so many others.

\section{Resistance}

This MRP would not be complete without discussing how Maasai women have been pushing back and resisting these discourses. Although that is rarely covered by researchers, community development workers and the media, Maasai women are attempting to speak up even though most of the time they are being silenced. A news article by Kenya standard newspaper (Githaiga, 2014) covered a story where 500 Maasai women took to the streets to protest against the anti-FGM campaigns. They wanted to be left alone to continue with their own lives. The media article about this protest did not give much coverage to the women but chose to focus on the reporters and how they were injured during the protest. This continues the silencing of Maasai women's voices.

The women used the means available to them to challenge the prevailing discourse but the institutions that further these discourses--i.e. the media that continues to perpetuate the dominant narrative. When people are constantly being treated as less, they will eventually find ways to resist. The anti-FGM discourse has silenced Maasai women even though this issue is about their bodies. Indigenous peoples all over the world have continued to experience oppression from their colonizers. Maasai women have continued to be discriminated against and treated as less in these campaigns but they have resisted it. 
Maasai girl as a victim who needs to be saved

As stated earlier, the anti-FGM campaigns have problematized Maasai culture and contributed to the marginalization of Maasai women. I agree with Njambi (2004) when she stated that the inherently imperialist global anti-FGM forces external to the continent monolithize African women as passive and in need of saving. In the film, although Maasai women are the subject they are silent and it is the men who are speaking on their behalf. As a Maasai woman, a feminist and a community activist, I was extremely disturbed by that. The chief Moran says a few times that they need to save the Maasai girl from FGM. In a community that is already patriarchal where women are constantly fighting to be heard, it is erroneous for an NGO to use donor money to give a man even more power to speak on behalf of the woman especially on an issue that is about women's bodies.

While I believe it is important for men to join the movement to fight for the rights of girls and women, this approach taken by AMREF is detrimental because it gives all the power to the man and victimizes the woman. Every time I see the images of the silent women in the film it reminds me of my own journey when I used to be afraid to speak up.

The warriors themselves speak about their experience when they were first trained to become peer educators and how they did not think they can do the job. They were unable to do the job because it did not sit well with their traditional values. It took much discussion with the trainers for the Morans to adopt their views. The fact that the Morans use the bible as their measure for what is acceptable or not acceptable culturally, shows that they have internalized colonial ideals. The fact that their definitions of success are now influenced by modern definitions of success means that this Anti-Cut Warriors phenomenon is not an organic 
expression or reaction of Maasai men to FC but rather an imposition of external ideas. Once again, the colonizer continues to control colonized minds and bodies.

Maasai women's bodies are a source of livelihood for these moran peer educators as well as NGOs. This is something I have outlined and discussed in a more detailed way in the literature review. AMREF retweeted this documentary and called Kanunga a 'beneficiary' of AMREF's programs. The majority of Kenyans tweeting about the documentary called Kanunga a hero and called for him to receive a national honour called the "Order of the Burning Spear'. None of the posts I read said anything about the women whose bodies were getting Kanunga such good media coverage and admiration for Kenyans. Maasai women's bodies in this documentary are objectified and commodified, and used as props. The Maasai warriors gain notoriety and are paid to be campaigners against FGM. AMREF uses their bodies to ask for more funds. It is interesting that AMREF which started as an organization to provide medical relief by air to remote communities did not use the medical approach to campaign against the harmful effects of FC. Instead it relied on existing oppressive power hierarchies to use men to tell women to stop practicing FGM since it makes economic sense whereas these same hierarchies continue to demand women to practice it since it makes cultural sense. Kanunga states how that eradicating FC will result in economic success for the community as more girls attend school and get wellpaying jobs.

Sewpaul (2006) states that while Globalization is presented as value free and a genderneutral process, its consequences are far from value free and gender neutral. Globalization especially that of neoliberal capitalism has contributed to distorted development between the North and the South to greater levels of inequality within nation states, to the further 
marginalization of women, and to a greater feminization of poverty especially among Black women (Sewpaul, 2006).

\section{Colonialism}

Hart (2009) stated that through colonization, Indigenous Peoples' worldviews are trivialized, our histories are rewritten from the eyes of the colonizer and our values are demeaned and manipulated. Razack (2004) also stated that racism is the contemporary story of the North assisting the South into modernity and this works so handily for the North in order to maintain its superiority. In the film, the Maasai "warriors" narrate how they were trained by AMREF to speak on their behalf and sell their agenda of eradicating FGM to the community. "I was trained by AMREF as a peer educator. I was taught the effects of FGM but I was afraid to speak about it since it is a tradition my grandmother and my mom have all gone through" (NTV Kenya, 2016, 3:11/23:07). "It was hard to initiate the anti-FGM Campaign but God gave me the strength to speak out" (NTV Kenya, 2016, 4:21/23:07).

Being leaders and men in a patriarchal society they are already in a position of power and I speculate that this may be why AMREF chose to hire men and women. They say that they are ambassadors for AMREF. As stated earlier, my focus is on the NGOs that drive the campaigns. I agree with Razack (2004) who stated that the West's participation depends on consigning a whole group of people into the category of those awaiting assistance into modernity.

The chief Moran in the film claims old traditions must come to an end and he says how the younger generation is opting for new ways of thinking and doing things. As a Maasai female who has both Western education and Maasai traditional education, this assertion is disturbing, not because eradicating FC is wrong, but because I worry that my community is being led to believe that our ways of thinking and doing are wrong and we must join what is considered the 
norm: Western Eurocentric worldviews. I agree with Hart (2009) when he stated that when individuals internalize colonization processes, they feel powerless and confused since they are pressured to detach from whom they are and are left with no means to alleviate the pressure. This film is a good example of how Indigenous histories are rewritten and their worldviews trivialized by colonialism. The practice of FC is rewritten by decontextualizing it from its history and its people. The Anti-Cut Warriors do not explore the reason why this practice has historically been undertaken by the community. They do not explore the cultural values and the spirit behind this practice that may be positive. Instead they in a wholesale manner brand it as evil and demean it. This is colonialism at its finest: decontextualizing Indigenous cultures, demeaning them and decimating them. Indeed, colonization attacks individuals on all levels; emotional, physical, mental and spiritual (Hart, 2009).

Women's bodies as battlegrounds and NGOs marketing objects

Njambi (2004), states that, historically female bodies have been colonial battlefields as seen in the rapes of Kenyan women by British colonial soldiers. She also states that racialized bodies have also been colonial battlefields as seen in the policing of cultural clothing of both colonized natives and slaves (Njambi, 2004). In this film, women's bodies are the center of the entire conversation yet the women in the film are mostly quiet and are only presented as victims who need to be saved.

Shrubb argues that this erasure of Indigenous peoples, their history and culture is a key trait of colonization (Shrubb, 2004). It is the first way that the anti-FGM discourse re-colonizes Maasai women as seen in the absence of and/lack of agency given to Maasai women's voices in the academic literature on FC. Secondly, historic knowledge production about FC and Maasai 
women is dominated by external actors and results in erasing the logic, rationale and historicity of why and how Maasai women practice(d) FC. 


\section{CHAPTER 5. IMPLICATIONS}

In this MRP, I examined the issue of FGM, and specifically, the discourses of international NGOs through the example of AMREF, that works on this issue in the Maasai community in Kenya. I employed the Maasai Female Experience where I brought my own voice and lived experiences as a Maasai woman growing up in this community and as an antioppression social worker. By doing so, I sought to be a knowledge co-creator with the Maasai community to create an alternative narrative of the Maasai women especially when it comes to FC. I believe this topic is important and will contribute to transformative anti-oppressive practice. As stated by Sewpaul (2006) in a rapidly globalizing world, as social workers we need to think and act both locally and globally.

Currently, anti-FGM campaigns are based on colonial Eurocentric perceptions of the Maasai woman that deny her personhood and agency. Also with increased migrations of populations, many women who have undergone FC are receiving services from systems based in North America that operate from a Eurocentric view. As social workers, we need to educate ourselves on global practices that affect the lives of our potential clients so that we can better advocate for them as they access services. This will also teach us to critique our own biases and teach us to continue approaching Indigenous Peoples and women as equals who have much to share and to teach us. As social workers, we need to educate and equip ourselves and connect with progressive social movements and communities while challenging inequalities rooted in international organizations and imperialists nations (Sewpaul, 2006).

My topic is an attempt to challenge these perspectives in order to reclaim the MFE narrative from Western feminist, philanthropist and racist approaches and resituate the Maasai Woman where she belongs: as author, definer and articulator of her own experience. Sewpaul 
(2006) also states that if we are to seek adequate solutions we need to engage with global structural forces. Social work does have a role to play in bridging the gap between the global and the local. The problems experienced by the people we work with are in large measure linked to structural sources of oppression, exclusion and poverty at the global level and if we are to seek adequate solutions we need to engage with global structural forces (Sewpaul, 2006).

The Anti-FGM discourse is a global phenomenon that unites people across sectors. It attracts people from the arts, law, social work, medical professions, anthropology, state actors, non-profit organizations, media institutions and career activists. As said earlier, I cannot assume to know the intentions of any of the actors, creators and perpetuators of Anti-FGM discourse. There may be a large number who are earnestly convinced that they are saving Maasai women and other women from cruel fates. There are a significant number for whom this discourse has been the source of fame, notoriety and funds. Fran Hosken is a good example of someone whose personal image overtook the images and voices of the people she stated that she was helping; and even when critiqued, she continued to manufacture problematic discourses. This paternalistic notion that others know what is best for the Maasai women is what this MRP has sought to understand, frame and critique. This MRP seeks to challenge those that seek to give Maasai women freedom over their own bodies to realize that freedom cannot be defined by Eurocentric views.

Ultimately as a Maasai woman, I can state that yes, the patriarchy in our community is so powerful that we cannot overcome it on our own. The patriarchy we experience due to the neocolonial and colonial assumptions placed on us globally is so powerful that we cannot overcome it on our own. What we do desire is the space to speak for ourselves. What we do desire is the space to decide about our bodies. What we do desire is the freedom from our culture 
and the external culture to allow us to do with our bodies as we want to. If we as individuals decide to take up FC, then our rights to do that should be loudly respected. If we as individuals decide not to undergo FC then that should not be seen as a moral victory of any sort. Rather it should be seen as just another woman making a personal decision over her body as she sees fit.

\section{Future Directions for Research}

Now that I have gained a deeper understanding of the current anti-FGM discourses, I feel that there are many directions for future research. The first would be to conduct a fuller critical discourse analysis of anti-FGM discourses, drawing from media, education initiatives and NGOs. The NTV documentary presented negative stereotypes about FC however this alone is not enough to define what a discourse is for this topic. I would like to see an examination of whether there are any differences or variations of the discourse geographically: i.e., are there differences between the discourse when it touches on Black women and when it touches Arab women? Are there differences between anti-FGM discourse targeted to a country like Kenya and the popular homegrown discourse in Kenya? I would also like to see if it is possible to create a chronological understanding of how FGM discourse has changed over the years to date.

The Maasai Female experience was missing in the literature as well as in the film. There is need for research that centers the Maasai female experience. I am interested to see interviews of Maasai women who have undergone FC and those who have not. I would be very interested in doing a qualitative study of women who have undergone FC to present their lived experience into the academic research. There are also a number of famous Maasai women like Josephine Kulea who have gained considerable fame, recognition and awards for their life stories where they escaped FC. I would like to also look at the impact these narratives have on Maasai women and on the dominant narrative of Maasai culture as a whole. Do these examples that are 
celebrated by Western media further perpetuate stereotypes of Maasai culture or do they challenge those notions?

\section{Recommendation and conclusion}

Finding a specific and culturally appropriate theoretical framework for this study was not an easy task as there do not appear to be many studies that employ relevant Indigenous methodological frameworks applicable to people of African worldviews. My intention was to adopt a theoretical framework that seeks liberation for Maasai women and that allows us to bring in our worldviews into the research. It is my hope that this research offers an opportunity for Maasai women to further engage in dialogue.

The Maasai Female Experience allowed me to bring into this research my own voice as a Maasai woman from the community that is being discussed in the film. The idea of the MFE allows for Maasai women to share insights about how we have sought to resist personal and social injustice directed to us by the anti-FGM campaigns. This study reveals how little is known about Maasai Female Experiences and worldviews. I hope this research can potentially contribute to raining awareness among researchers and community development workers.

One recommendation could be for researches to stop using FGM and adopt the valueneutral FC instead. FGM was created by Fran Hosken (Hosken, 1993) as a sensationalized term that monothilized a vast number of cultural practices so that she could get more awareness for her cause. The fact that it was her personal cause and that she resisted critique when others told her she was in the wrong to judge other cultures based on a Western worldview means that this is a term loaded with personal prejudices and as such should have no place in academia.

A related recommendation is for researchers on FGM to ensure that they give voice and agency in to Maasai women instead of speaking for them--not only for Maasai women but other 
women from cultures that practice FC. FC researchers should seek to present these women's voices without mediating them with their own personal experiences. It would be equally important for NGOs and creators of anti-FGM discourse to stop using images of Maasai women, girls and culture as the face of their campaigns and to instead allow other cultures affected by FC to speak for themselves.

Finally, it would be important for the academic community to realize that women from Indigenous cultures such as the Maasai face a particular set of intersectional oppressions due to their Indigeneity, living on contested lands, their bodies being battlegrounds for modern and traditional values, and double patriarchy, and to incorporate this into their work. Also important is to have more research into how legislation of FC negatively affects communities that practice it.

This MRP has been a source of great personal transformation for me. It has been extremely disheartening to find Maasai culture and Maasai women being rendered invisible in the academic literature. The amount of misinformation I found about my people while doing my research was almost immobilizing and led to a lot of stress. This MRP however has also been an opportunity to speak back to power with my lived experience as a Maasai woman and to challenge the colonial notions that still affect the lives of my people. It has been an opportunity to learn of others who have gone before me like Wairimũ Ngaruiya Njambi who wrote on Dualisms and Female Bodies in Representations of African Female Circumcisions (2004). It has given me an opportunity to understand current scholarship on the topic, improve my ability to comprehend and write research and also wrestle with how to combine academic knowledges and lived experience in a way that allows me to be a co-creator with Maasai women to create a narrative where we are the authors, articulators and definers of our own narrative. 


\section{REFERENCES}

28toomany.org. (2017). 28 Too Many - FGM lets end it - Our Annual Reports and Accounts. [online] Available at: http://28toomany.org/about-28toomany/our-annual-reports-andaccounts/

Ajayi-Soyinka, O. (1993). Black feminist criticism and drama: thoughts on double patriarchy. Journal of Dramatic Theory and Criticism, 7(2), 161-176.

Allbutt, T. C., \& Playfair, W. S. (Eds.). (1896). A System of Gynaecology (Vol. 2). Macmillan.

Angermuller, J., Maingueneau, D., \& Wodak, R. (Eds.). (2014). The discourse studies reader: Main currents in theory and analysis. John Benjamin Publishing Company.

Asante, M. K. (1998). The Afrocentric Idea. Philadelphia: Temple University Press.

Asante, Molefi K. (1987). The Afrocentric idea. Philadelphia: Temple University Press.

Asante, Molefi K. (1988). Afrocentricity (Revised. Ed.). Trenton, NJ: Africa World Press

Davis, S.K., Williams, A.D. \& Akinyela, M. (2009). An Afrocentric approach to building cultural relevance in social work research. Journal of Black Studies, 41(2), 338350.

Davis, K. (2004). Responses to W. Njambi's 'Dualisms and female bodies in representations of African female circumcision: a feminist critique': Between moral outrage and cultural relativism. Feminist Theory, 5(3), 305-311.

Fairclough, N. (2003) Analysing Discourse: Textual Analysis for Social Research. London: Routledge

Fairclough, N. (1992). Discourse and Social Change. Cambridge: Polity Press. FGM in Kenya (2013, May). 28 Too Many. Retrieved July 18, 2017 from 
http://28toomany.org/media/uploads/final kenya country profile may 2013.pdf

Githaiga, P (2014, June 5) Over 500 Maasai women protest FGM ban. Standard Digital Retrieved July 24, 2017 from https://www.standardmedia.co.ke/article/2000123627/over- 500-maasai-womenprotest-fgm-ban

Gatens, M. (1996). Imaginary bodies: Ethics, power and corporeality. London: Routledge.

Gona, G. (Ed.). (2014). (Re)membering Kenya Vol 2: Interrogating Marginalization and Governance. Twaweza Communications.

Gunning, I. R. (1992) Arrogant Perception, World-Travelling and Multicultural Feminism: The Case of Female Genital Surgeries. Columbia Human Rights Law Review, 23, 189-248.

Hart, M. A. (2009). Anti-colonial Indigenous social work: Reflections on an Aboriginal approach. Wicihitowin: Aboriginal social work in Canada, 25-41.

Hosken, F. (1993) The Hosken report: Genital and sexual mutilation of females. Lexington, MA: Women's International Network News

Hooks, b. (1982). Ain't I a Woman: Black Women and Feminism. Winchester, MA: Pluto Press.

Jhamtani, H. (1991). Redefining feminism as the women's movement. Asian Studies Review, 15(1), 96-100.

Kalev, H. D. (2004). Cultural rights or human rights: The case of female genital mutilation. Sex Roles, 56 (5/6), 339-348.

Krivenko, E. Y. (2015). Rethinking human rights and culture through female genital surgeries. Human Rights Quarterly, 37(1), 107-136.

Kenyatta, J. (1959). Facing Mount Kenya. London: Secker and Warburg.

Kipling, R. (1956). Kipling: a selection of his stories and poems (Vol. 2). New York: Doubleday. 
Korieh, C. (2005). “Other” bodies: Western feminism, race and representation in female circumcision discourse. In O. Nnaemeka (Ed.), Female circumcision and the politics of knowledge. Westport, CT: Praeger.

Kumsa, M. K. (2008). Social working the dance of otherness. Canadian Social Work Review, 25(1), 97-106.

Mkabela, Q. (2005). Using the Afrocentric method in researching Indigenous African culture. The Qualitative Report. 10(1), 178-189

Mullaly, B. (2002). Challenging oppression: A critical social work approach. London: Oxford University Press.

Nandy, A. (1988). The intimate enemy: Loss and recovery of self under colonialism (Vol. 251). Delhi: Oxford University Press.

Nnaemeka, O. (January 01, 1994). Bringing African women into the classroom: Rethinking pedagogy and epistemology. Borderwork, 301-318.

Njambi, W. N. (2004) Dualisms and female bodies in representations of African female circumcision: A feminist critique. Feminist Theory, 5(3), 281-303.

Razack, S. (2004). Dark threats and white knights: The Somalia affair, peacekeeping, and the new imperialism. Toronto: University of Toronto Press.

Obituary of Fran Hosken.

http://archive.boston.com/news/globe/obituaries/articles/2006/02/12/fran p hosken 86 activist for womens issues globally/

Nnaemeka, O. (2005). Female circumcision and the politics of knowledge: African women in imperialist discourses. Westport, CT: Praeger Publishers 
Schneider, D. M. (1955). Psychoethnography: Symbolic wounds, puberty rites and the envious male. American Anthropologist, 57(2), 390-392.

Poole, J. M. (2007). Behind the rhetoric of hope: A critical analysis of recovery discourses in Ontario. Halifax: Fernwood Publishers.

Sewpaul, V. (2006). The global-local dialectic: challenges for African scholarship and social work in a post-colonial world. British Journal of Social Work, 36(3), 419-434.

Shrubb, R. (2014). “Canada has no history of Colonialism.” Historical Amnesia: The Erasure of Indigenous Peoples from Canada's History (Doctoral dissertation).

Traweek, S. (1992). Border Crossings: Narrative Strategies in Science Studies and Among High Energy Physicists at Tsukuba Science City, Japan. In A. Pickering (Ed.), Science as Practice and Culture (pp.429-465). Chicago: University of Chicago Press.

Van Dijk, T. A. (1993). Principles of critical discourse analysis. Discourse \& Society, 4(2), 249283.

Wehbi, S., \& Taylor, D. (2012). Photographs speak louder than words: the language of international development images. Community Development Journal, 48(4), 525-539.

Wodak, R., \& Meyer, M. (Eds.). (2015). Methods of critical discourse studies. Sage. World Health Organization. (2017). Female genital mutilation. Available at: http://www.who.int/mediacentre/factsheets/fs241/en/

Youtube (2017). Anti - cut warriors of the Maasai community. [image] Available at: https://www.youtube.com/watch?v=aAcQDX6dTCI 